TITLE:

\title{
Anionic effect of ionic liquids electrolyte on electrochemical behavior of ferrocenylthiol/alkanethiol binary SAMS
}

\section{$\operatorname{AUTHOR}(\mathrm{S})$ :}

Sun, Qing-Wei; Murase, Kuniaki; Ichii, Takashi; Sugimura, Hiroyuki

\section{CITATION:}

Sun, Qing-Wei ...[et al]. Anionic effect of ionic liquids electrolyte on electrochemical behavior of ferrocenylthiol/alkanethiol binary SAMs. Journal of Electroanalytical Chemistry 2010, 643(1-2): 58-66

\section{ISSUE DATE:}

2010-05-01

URL:

http://hdl.handle.net/2433/128761

\section{RIGHT:}

(C) 2010 Elsevier B.V.; This is not the published version. Please cite only the published version.; この論文は出版社版でありません。引用の際に は出版社版をご確認ご利用ください。 


\title{
Anionic Effect of Ionic Liquids Electrolyte on Electrochemical Behavior of Ferrocenylthiol / Alkanethiol Binary SAMs
}

\author{
Qing-Wei Sun, Kuniaki Murase*, Takashi Ichii, Hiroyuki Sugimura* \\ Department of Materials Science and Engineering, Kyoto University \\ 36-1 Yoshida-hommachi, Sakyo-ku, Kyoto 606-8501, Japan
}

\begin{abstract}
Redox behaviors of binary self-assembled monolayers (SAMs) consisting of ferrocenyland methyl-terminated alkanethiols on gold were investigated in three different ionic liquids (ILs) and were compared with the behaviors in an aqueous $\mathrm{HClO}_{4}$ solution. A set of cyclic voltammograms showed that, when the surface density of ferrocenyl-groups was relatively high, the shape of redox waves (e.g. peak area and peak broadening towards positive potential) for the ferrocenyl-groups was strongly affected by the anion size of the ILs, suggesting that the compensation of surface positive charge emerged when oxidized to ferrocenium state is sterically-hindered in the case of large anions like bis[(trifluoromethyl)sulfonyl]amide (TFSA ${ }^{-}$). This is supported by the fact that the anion-size effect disappeared if the density of ferrocenyl-groups was diluted. A potential-step chronocoulometry was concomitantly

\footnotetext{
* Corresponding authors.

E-mail addresses: kuniaki.murase@a0017299.mbox.media.kyoto-u.ac.jp (K. Murase), hiroyuki.sugimura@materials.mbox.media.kyoto-u.ac.jp (H. Sugimura)
} 
employed to estimate the net faradaic charge of the redox. The redox behaviors in mixed ILs containing two different sized anions also gave clear evidence that smaller anions, e.g. $\mathrm{BF}_{4}^{-}$ions, have a greater tendency to make ion pairs with ferrocenium moieties.

Keywords: ionic liquids; self-assembled monolayers; mixed monolayers; ferrocenyl alkanethiol; redox properties

\section{Introduction}

Electrochemically active self-assembled monolayers (SAMs) [1-2] prepared on gold (Au) surfaces from ferrocene-terminated alkanethiols [3-6] bear not only scientific interest, but they have also attracted much interest in recent years for their application in, for example, sensors and molecular electronic devices. The preparation of mixed (e.g. binary) SAMs of such ferrocenyl-terminated alkanethiols with methyl-terminated alkanethiols is a useful technique to define the surface compositions of active and inactive species in order to control the function of the devices [7-10]. Redox behaviors of these SAMs have been well-studied by cyclic voltammetry (CV) using aqueous electrolytes such as $\mathrm{HClO}_{4}$ [11,12]. However, the aqueous electrolytes have limitations of potential window width $(1.23 \mathrm{~V}$ in theory) and operational temperature range $\left(0-100{ }^{\circ} \mathrm{C}\right.$ under normal pressure), which can restrict the SAMs' application. 
We thus focused on ionic liquids (ILs), which are currently the subject of considerable attention as a new "green" electrolyte for electrochemical science and engineering [13-15]. Most ILs have a wider potential window (up to $\sim 5 \mathrm{~V}$ ) and a higher thermal stability (up to $450{ }^{\circ} \mathrm{C}$ ) $[16,17]$, so the use of ILs would maximize the performance of electrochemically active SAMs and contribute to their long-term stability when applied to some electronic devices. Although studies are in progress concerning the combination of SAMs and ILs such as SAMs formation in ILs [18], desorption behavior in ILs [19,20], and redox behavior in ILs [21], a comparative study on the redox behavior of electrochemically active SAMs in several different types of ILs has not been conducted so far. In the present work, we attempted to elucidate the interaction of ferrocenyl headgroup (Fc) with ILs, especially with their anions when in an oxidized ferrocenium $\left(\mathrm{Fc}^{+}\right)$state, through a systematic study on the redox of SAMs in several different ILs.

Previously, we investigated the redox behavior of pure 11-ferrocenyl-1-undecanethiol (FUT) SAMs on $\mathrm{Au}(111)$ surface in a quaternary ammonium-imide type IL, trimethyl- $n$-hexylammonium bis[(trifluoromethyl)sulfonyl]amide (TMHA-TFSA; note that the $\mathrm{TFSA}^{-}$anion is sometimes described as $\mathrm{TFSI}^{-}$or $\mathrm{Tf}_{2} \mathrm{~N}^{-}$where $\mathrm{Tf}=\mathrm{SO}_{2} \mathrm{CF}_{3}$ ), and several differences in electrochemical behaviors were found between the IL and aqueous systems. For instance, the Fc groups of pure 11-ferrocenyl-1-undecanethiol (FUT) SAM gave a smaller redox peak area in TMHA-TFSA than those in aqueous $\mathrm{HClO}_{4}$ solution, in spite of the same surface coverage of the FUT molecule, possibly suggesting that fewer FUT 
molecules were involved in the redox. One plausible reason for this phenomenon is steric hindrance of large-sized TFSA ${ }^{-}$anions, when they compensate for the positive charge emerging at ferrocenium moieties as $\mathrm{Fc} \square \mathrm{Fc}^{+}+$e. In that case, the anions should come closer to each $\mathrm{Fc}^{+}$moiety without hindrance $\overline{\text {; }}$ if the FUT molecules are sparsely-distributed on the surface through a uniform dilution of surface concentration using electrochemically inert molecules. To verify this assumption, we used 1-undecanethiol (UDT) as a supply of methyl-terminated electrochemically inert thiol molecules to prepare FUT/UDT binary SAMs with various surface concentrations of FUT. Meanwhile, because the anionic species in aqueous systems are known to affect the redox behavior of ferrocenylthiol SAMs [7,22], we also investigated the electrochemical behavior of these binary SAMs in three different ILs with different combinations of anion and cation, TMHA-TFSA, 1-ethyl-3-methylimidazolium bis[(trifluoromethyl)sulfonyl]amide (EMI-TFSA), and 1-ethyl-3-methylimidazolium tetrafluoroborate $\left(\mathrm{EMI}_{-} \mathrm{BF}_{4}\right)$, and compared with the behavior in an aqueous system. We also tried using a mixture of EMI-TFSA and EMI-BF 4 to demonstrate the clear effect of anions.

\section{Experimental}

The ionic liquid TMHA-TFSA was synthesized by the reaction of trimethyl- $n$-hexylammonium bromide (TMHA-Br; Tokyo Chemical Industry, 98\%) with lithium bis[(trifluoromethyl)sulfonyl]amide (Li-TFSA; Fluka, 99\%) in aqueous 
solution. The preparation procedure was as described in our previous paper [23]. The ready-made ILs, EMI-BF $4(\geq 97 \%)$ and EMI-TFSA ( $\geq 98 \%)$, were obtained from Tokyo Chemical Industry and Merck, respectively.

The Au substrates were prepared by vacuum deposition: Gold film of thickness 150 $\mathrm{nm}$ was deposited on cleaved natural mica substrates in a vacuum (about $10^{-6} \mathrm{~Pa}$ ) at 450 ${ }^{\circ} \mathrm{C}$ to obtain an $\mathrm{Au}(111)$ surface. The FUT/UDT binary SAMs were prepared by the coadsorption method: freshly deposited $\mathrm{Au}(111)$ substrates were immersed in mixed ethanol solutions of FUT (Dojindo, 95\%) and UDT (Aldrich, 98\%) with $1 \mathrm{mM}(\mathrm{M}=$ mol $\mathrm{dm}^{-3}$ ) total thiol concentration for at least $24 \mathrm{~h}$, followed by rinsing with ethanol. The FUT:UDT molar concentration ratios in the solution were adjusted to 10:0, 9:1, 5:5, 1:9, and $0: 10$, that is to say the FUT mole fractions $\left(\chi_{\mathrm{FUT}}\right)$ in each solution were 1.0, 0.9, $0.5,0.1$, and 0.0 , respectively.

X-ray photoelectron spectroscopy (XPS, Kratos Analytical, ESCA3400) measurement was performed for the resulting binary SAMs to analyze the surface elemental compositions of iron (Fe 2p), sulfur (S 2p), and carbon (C 1s). The XPS system was equipped with an X-ray source $(\mathrm{Mg}-\mathrm{K} \alpha)$, operated at $10 \mathrm{~mA}$ and $10 \mathrm{kV}$. All the spectra acquired were calibrated according to the $\mathrm{Au}$ if band, where the signal for bulk $\mathrm{Au}^{0}$ peaks at $84.0 \mathrm{eV}$. Gaussian-Lorentzian peak deconvolution and fitting were performed for quantitative analyses of the spectra after subtracting each background.

The electrochemical measurements including $\mathrm{CV}$ and potential-step chronocoulometry were carried out using an integrated electrochemical analyzer 
ALS/CHI model $660 \mathrm{C}$ connected to a conventional three-electrode cell. Four different electrolytes were used: $0.1 \mathrm{M} \mathrm{HClO}_{4}$ (Nacalai Tesque) aqueous solution and three types of ILs, TMHA-TFSA, EMI-TFSA, and EMI-BF 4 . All the electrolytes were deaerated by $\mathrm{N}_{2}$ gas purging for 30 min prior to the measurements and by $\mathrm{N}_{2}$ gas flowing above the surface of electrolytes during the measurements. An $\mathrm{Ag} / \mathrm{AgCl}(3 \mathrm{M} \mathrm{NaCl})$ electrode was used as reference electrode in the aqueous $\mathrm{HClO}_{4}$ solution, while for the measurement performed in ILs electrolytes, we used Pt wires immersed in each IL as quasi-references [24]. Because of the usage of different reference electrodes, the absolute potentials of $\mathrm{CV}$ peaks observed in different electrolytes cannot be compared for discussion; we only discuss the area and broadening of the redox peaks in the present study.

Integration of the redox peak area of cyclic voltammograms (CVs) is a common method to estimate the amount of electrochemically active species adsorbed on an electrode. However, a background current due to non-faradaic double layer charging sometimes reduces the accuracy of the amount of the redox-active adsorbate. To solve this problem, Bard et al. invented a sophisticated technique using potential-step chronocoulometry, which successfully eliminates the double layer charging, if any, from the electrochemical reaction of the adsorbate when no diffusing species is involved $[25,26]$. In the present study, chronocoulometry for several SAM samples in the electrolytes was also attempted in order to estimate the amount of electrochemically active FUT adsorption, and to reinforce the data of CV. 
In order to investigate the anionic effect of ILs, CV for the binary SAMs were also performed using mixtures of two ILs with the same cation but different anion species; here, the mixed ILs were prepared by adding EMI-BF 4 to EMI-TFSA at the volume

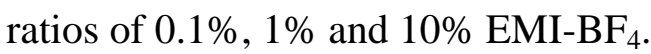

\section{Results and Discussion}

\subsection{SAM formation: XPS measurements}

While thiol SAM formation on $\mathrm{Au}$ substrate is a well-established and foolproof process, we first checked the adsorption of thiol molecules by conventional XPS measurements after each SAM preparation. Figure 1 shows a set of Fe $2 p$ and $S 2 p$ spectra for five SAMs prepared using the solutions with five different $\chi_{\text {FUT }}$, and those for bare Au substrate. For the SAMs formed in the solution containing FUT molecules $\left(\chi_{\mathrm{FUT}}=0.1-1.0\right)$, a pair of peaks were observed at binding energies of 709 and $722 \mathrm{eV}$, which were assigned to $\mathrm{Fe}(\mathrm{II}) 2 \mathrm{p}_{3 / 2}$ and $\mathrm{Fe}(\mathrm{II}) 2 \mathrm{p}_{1 / 2}$, respectively; peaks due to $\mathrm{Fe}(\mathrm{III})$ state, which if present should appear at 711 and $724 \mathrm{eV}$, were not recognized, suggesting that FUT molecules are confined to the surface without observable oxidation. The intensity of the two Fe $2 p$ peaks decreased along with decreasing $\chi_{\text {FUT }}$. In contrast, the $S 2 p$ peak at around $163 \mathrm{eV}$ maintained almost constant intensity despite the $\chi_{\text {FUT }}$ change, indicating that equivalent amounts of total thiols were adsorbed on the $\mathrm{Au}$ surface while the surface concentration of Fc group, i.e., the FUT molecule, was decreased by diluting FUT with UDT in solution. 
The atomic compositions of $\mathrm{Fe}, \mathrm{S}, \mathrm{C}$, and $\mathrm{Au}$ are listed in Table 1. It is reasonable to suppose that the values of $\mathrm{S}$ and Fe for each SAM reflect the respective amounts of total thiols and the FUT molecules adsorbed on the Au surface, hence the surface FUT mole fraction can be given by the Fe/S composition ratio. To compare the surface FUT mole fraction with that in the solution used for SAM preparation, the Fe/S composition ratios were plotted against $\chi_{\text {FUT }}$ (left axis of Fig. 2); here, we normalized the $\mathrm{Fe} / \mathrm{S}$ value for $\chi_{\mathrm{FUT}}=1.0$ to be 1 (see rightmost column of Table 1 ). A nearly linear, or slightly convex-upward relationship was recognized between the FUT fraction on the Au surface and that in solution, suggesting that FUT and UDT molecules were adsorbed on the Au surface with roughly the same ratio in each solution. Generally, in the case of binary SAMs formation from two types of molecules with the same alkyl chain length, the reported trend is that such molecules adsorb at a similar fraction to that in solution [27], and our FUT/UDT binary SAM followed the same trend. Consequently, for the sake of convenience, we use $\chi_{\text {FUT }}$ values to indicate specific SAMs instead of the measured surface FUT fraction.

\subsection{Cyclic voltammetry with a typical scan range}

Figure 3 shows CVs for the five SAMs measured in the four different electrolytes. A pair of anodic and cathodic waves due to the redox of Fc groups was observed for each SAM except for pure UDT SAM $\left(\chi_{\mathrm{FUT}}=0\right)$. The separation between the anodic and cathodic peaks is quite small for each SAM, and a linear relationship was found between the scan rate and both of the peak currents (data not shown here), providing 
evidence that the waves were due to redox of the adsorbed, i.e. surface-confined, species. Regarding the aqueous $\mathrm{HClO}_{4}$ solution, peak splitting was observed for SAMs with $\chi_{\text {FUT }}$ of $1.0,0.9$, and 0.5 , indicating that surface Fc groups exist in two different states. Lee et al. [11] and Fujii et al. [28] reported that the peak at the more positive potential derives from "clustered" ferrocenyl molecules forming densely packed domains, while that at the more negative potential comes from "isolated", or sparse, ferrocenyl molecules at the edge, or the boundary, of the domains. In our case, the peak at $+0.37 \mathrm{~V}$ vs. $\mathrm{Ag} / \mathrm{AgCl}(3 \mathrm{M} \mathrm{NaCl})$ corresponded to the domain of FUT molecules, and that at $+0.27 \mathrm{~V}$ to the FUT molecules on the boundary of the FUT domain or surrounded by UDT molecules. It should be noted that the peak at $+0.37 \mathrm{~V}$ disappeared when $\chi_{\text {FUT }}$ was 0.1 , indicating that all FUT molecules in this case were well-dispersed by electrochemically inert UDT molecules. In contrast, such peak splitting behavior for FUT-rich SAMs $\left(\chi_{\text {FUT }} \geq 0.5\right)$ was not observed in EMI-TFSA and TMHA-TFSA electrolytes, in which the CV peaks appeared broad, like the peak at $+0.27 \mathrm{~V}$ for the aqueous $\mathrm{HClO}_{4}$ solution, and showed a long tail toward higher potential (see Figs. 3c and 3d) as discussed later. On the other hand, EMI-BF 4 electrolyte gave an intermediate behavior; peak splitting was not clearly observed, but instead, a weak shoulder was found, for example, at $+0.25 \mathrm{~V}$ vs. Pt for $\chi_{\mathrm{FUT}}=1.0$ on the positive side of the main peak at $+0.20 \mathrm{~V}$.

It was also found that both the peak height and peak area decreased with decreasing $\chi_{\text {FUT }}$ in all electrolytes. In addition, CV for FUT-rich SAMs measured in ILs electrolytes with $\mathrm{TFSA}^{-}$anion showed a smaller peak height and peak area compared to 
that measured in $\mathrm{HClO}_{4}$ and $\mathrm{EMI}-\mathrm{BF}_{4}$, while the peak height and area remained almost identical in all four electrolytes when the FUT molecules were well-dispersed by UDT $\left(\chi_{\mathrm{FUT}}=0.1\right)$.

To assess the surface density $N_{\text {FUT }}$ of electrochemically active FUT species involved in the redox (i.e. $\mathrm{Fc}^{+}+\mathrm{e}=\mathrm{Fc}$ ), the total electricity $(Q)$ of the redox was obtained by integrating the oxidative peak, and converted to $N_{\mathrm{FUT}}$ by

$$
N_{\mathrm{FUT}}=\frac{Q}{n e A}
$$

where $e$ is the elementary charge, $A$ is the electrode surface area, and $n(=1)$ is the number of electrons involved in the redox. The resulting $N_{\mathrm{FUT}}$ values for each binary SAM are plotted against $\chi_{\mathrm{FUT}}(\mathrm{Fig} .4 \mathrm{a})$. In the case of pure FUT SAM $\left(\chi_{\mathrm{FUT}}=1.0\right)$ in the aqueous $\mathrm{HClO}_{4}$ solution, the $N_{\mathrm{FUT}}$ value is $2.8 \times 10^{14} \mathrm{~cm}^{-2}$, which is very close to the ideal surface coverage for ferrocenylthiol SAMs, $2.7 \times 10^{14} \mathrm{~cm}^{-2}$ [29], while the $Q$ value may involve a small amount of non-faradaic component (see Section 3.4). This indicates that the $N_{\mathrm{FUT}}$ in this case reflects the real surface coverage of FUT molecules. In other words, almost all the FUT molecules at the $\mathrm{Au}(111)$ surface underwent redox during the CV scan within the potential scan range of Fig. 3. Consequently, we can regard the $N_{\mathrm{FUT}}$ values for $\chi_{\mathrm{FUT}}=0.1-1.0$ samples in the aqueous $\mathrm{HClO}_{4}$ solution as the real surface coverages, $\Gamma_{\mathrm{FUT}}$, of FUT molecules; a typical assumption in surface electrochemistry. In Fig. 2 (right axis), the $\Gamma_{\text {FUT }}$ values are also plotted against $\chi_{\text {FUT, }}$, showing the same trend as the results from XPS measurement. This substantiated again that the FUT was adsorbed on the Au surface, showing almost the same FUT 
fraction in each solution used for SAM preparation.

When assessed from Fig. $4 \mathrm{a}$, the $N_{\mathrm{FUT}}$ values in $\mathrm{EMI}-\mathrm{BF}_{4}$ electrolyte were similar to those in the aqueous $\mathrm{HClO}_{4}$ solution, while $N_{\mathrm{FUT}}$ in both TMHA-TFSA and EMI-TFSA followed another trend. In these ILs with $\mathrm{TFSA}^{-}$anion, $N_{\mathrm{FUT}}$ values for FUT-rich SAMs were smaller (i.e. about $70 \%$ ) compared to those in the aqueous $\mathrm{HClO}_{4}$ solution or EMI-BF 4 , suggesting that fewer FUT molecules were involved in the redox reaction. In contrast, the SAM with dispersed FUT molecules $\left(\chi_{\mathrm{FUT}}=0.1\right)$ gave approximately the same $N_{\text {FUT }}$ values around $5 \times 10^{13} \mathrm{~cm}^{-2}$, regardless of the electrolytes used.

One possible explanation for this interesting fact is that, if all the $\mathrm{Fc}$ headgroups on the SAM surface are oxidized to $\mathrm{Fc}^{+}$state, large-sized $\mathrm{TFSA}^{-}$anions cannot thoroughly compensate for the positive charge through the formation of $\mathrm{Fc}^{+}-\mathrm{TFSA}^{-}$ion pairs, especially in the case of Fc groups on closely packed FUT domains. According to the effective ion radius reported [30], TFSA ${ }^{-}$anion $(0.325 \mathrm{~nm})$ has a larger size than those of $\mathrm{BF}_{4}{ }^{-}$anion $(0.229 \mathrm{~nm})$ and $\mathrm{ClO}_{4}{ }^{-}$anion $(0.237 \mathrm{~nm})$. At the same time, the effective radius of the neutral $\mathrm{Fc}$ group is reported to be $0.33 \mathrm{~nm}$ [29]. Therefore, we can assume that $\mathrm{BF}_{4}^{-}$and $\mathrm{ClO}_{4}{ }^{-}$anions can more easily access $\mathrm{Fc}^{+}$groups in a one-on-one fashion and form complete $\mathrm{Fc}^{+}-\mathrm{BF}_{4}^{-}$or $\mathrm{Fc}^{+}-\mathrm{ClO}_{4}^{-}$ion pairs without steric hindrance, so the redox peak areas in those electrolytes showed the real values of FUT surface coverage.

\subsection{Cyclic voltammetry with a wide potential scan range}


As mentioned above, CVs for FUT-rich SAMs $\left(\chi_{\mathrm{FUT}} \geq 0.5\right)$ in $\mathrm{TFSA}^{-}$based ILs exhibited a long tail toward the higher potential region (see Figs. $3 \mathrm{c}$ and $3 \mathrm{~d}$ ). This tail implies that the oxidation of $\mathrm{Fc}$ groups and concomitant $\mathrm{Fc}^{+}-\mathrm{TFSA}^{-}$ion pairing still takes place gradually in this potential region. Considering this phenomenon, it occurred to us that unreacted Fc groups within the CV scan of Fig. 3 would receive compensation if more positive potentials were applied. Even if there were no room to form $\mathrm{Fc}^{+}-\mathrm{TFSA}^{-}$one-to-one pairings, it is expected that a piled accumulation of the anions in the vicinity of the SAM surface would form a large reservoir of negative charge, which could compensate the positive charges emerging at the other Fc groups. To verify this assumption, the positive scan limit was enlarged to $+0.8 \mathrm{~V}$ for FUT-rich SAMs measured in TMHA-TFSA and EMI-TFSA (Fig. 5). It should be noted here that, because of the wide electrochemical window of TFSA ${ }^{-}$based ILs, i.e. $5.0 \mathrm{~V}$ for TMHA-TFSA and 4.6 V for EMI-TFSA [18], we can apply such positive potentials without any decomposition of electrolytes, unlike the case of aqueous media, where the anodic potential is limited by oxygen evolution. For the SAMs with $\chi_{\mathrm{FUT}}=0.5$ in TMHA-TFSA, the anodic current converged to the non-faradaic background current at around $+0.3 \mathrm{~V}$ vs. Pt on the positive-going scan and the onset of cathodic current was found at the same potential after switching the scan (see Fig. 5a). With the increase in $\chi_{\text {FUT, }}$ the current convergence potential shifted to higher potential. A similar phenomenon was also observed in EMI-TFSA (Fig. 5b). We suggest that the unreacted Fc groups within the potential scan range of Fig. 3 were oxidized gradually at potentials higher than $+0.3 \mathrm{~V}$. In these cases, however, no extra "peak" emerged at the 
high potential region; hence it would appear that the reaction is not a potential-sensitive quantitative ion-pairing process. Regarding these TFSA $^{-}$based ILs, the surface density, $N_{\mathrm{FUT}}$, of electrochemically active FUT moieties estimated by Eq. (1) was again plotted in Fig. $4 \mathrm{~b}$ as a function of $\chi_{\text {Fut. }}$ Here, each $Q$ value was obtained by integrating the oxidative current of the enlarged voltammograms (Fig. 5), and the resulting $N_{\text {FUT }}$ values were compared with those based on Figs. $3 \mathrm{c}$ and $3 \mathrm{~d}$. Of importance to note is that the new $N_{\text {FUT }}$ values for FUT-rich SAMs $\left(\chi_{\text {FUT }} \geq 0.5\right)$ were always larger than those obtained from Figs. $3 c$ and $3 d$ and approached the values for the aqueous $\mathrm{HClO}_{4}$ solution or $\mathrm{EMI}^{-\mathrm{BF}_{4}}$.

Figure 6 schematically illustrates how the large-sized $\mathrm{TFSA}^{-}$anions contribute to the redox process of FUT SAM $\left(\chi_{\mathrm{FUT}}=1.0\right)$ : (I) The anions $\left(\mathrm{TFSA}^{-}\right)$and cations $\left(\mathrm{TMHA}^{+}\right.$or $\left.\mathrm{EMI}^{+}\right)$are randomly distributed when no potential is applied; (II) the Fc groups start to be oxidized on the forward scan and, at the potential of the anode peak, about a half of the FUT on the domain boundary and a part of the FUT inside the domain are oxidized by forming ion pairs with TFSA $^{-}$anions; (III) at the end of the anode peak, TFSA ${ }^{-}$anions form a complete monolayer in contact with surface Fc groups when the ion-pairing process comes to an end, but still cannot compensate for all the Fc groups if oxidized; (IV) by applying higher potentials, a larger amount of anions accumulate progressively to the second layer depending on the potential, pushing cations away and causing an enhanced negative charge atmosphere, which contributes further compensation for the remaining Fc groups. By contrast, in the case of FUT-dispersed SAM $\left(\chi_{\mathrm{FUT}}=0.1\right), \mathrm{TFSA}^{-}$anions can access Fc readily to form ion pairs 
without any steric hindrance, because of the separation of surface Fc groups. On the other hand, small-sized $\mathrm{BF}_{4}^{-}$anions would be able to make a complete array to compensate all Fc groups through the first layer in contact with SAMs surface, regardless of the $\chi_{\text {FUT }}$ value. In this case, all of the FUT molecules adsorbed on the substrate are involved in the redox process without extending the potential scan.

Since steric hindrance might be a principal cause of the phenomenon discussed above, we suggest that the variation of the peak splitting behavior shown in Fig. 3 is also related to anion size. ILs with TFSA $^{-}$anion, a very "soft" anion, are not as chemically sensitive as $\mathrm{EMI}-\mathrm{BF}_{4}$ and the aqueous $\mathrm{HClO}_{4}$ solution from the aspect of interaction with the different states (i.e. "clustered" or "isolated") of surface adsorbate. While the peak splitting in $\mathrm{EMI}^{-\mathrm{BF}_{4}}$ (Fig. 3b) is rather vague compared to that in aqueous $\mathrm{HClO}_{4}$ solution, these two electrolytes with similar sized anions, $\mathrm{BF}_{4}^{-}$and $\mathrm{ClO}_{4}^{-}$, can more or less distinguish the different states of FUT molecules.

\subsection{Potential-step chronocoulometry}

In the above discussion, $N_{\text {FUT }}$ values were derived from the total electricity data $(Q)$ found by a simple numerical integration of the oxidative waves. Hence, the $Q$ data can involve a non-faradaic component, to a greater or lesser extent, due to electrical double layer charging $\left(Q_{\mathrm{dl}}\right)$, as mentioned in Experimental; especially in the cases of the enlarged voltammograms (Fig. 5), the $Q_{\mathrm{dl}}$ may have a larger contribution to the overall $Q$ value due to the wider integration range. Accordingly, we also conducted potential-step chronocoulometry. 
The initial potential $E_{\mathrm{i}}$ for the potential-step method $[25,26]$ was set at the negative foot of the oxidation wave, where no redox reaction occurred; in the case of aqueous 0.1 $\mathrm{M} \mathrm{HClO}_{4}$ solution, for example, $E_{\mathrm{i}}$ was fixed at $0.0 \mathrm{~V}$ vs. $\mathrm{Ag} / \mathrm{AgCl}(3 \mathrm{M} \mathrm{NaCl})$ based on Fig. 3. The potential was then stepped from $E_{\mathrm{i}}$ to $E_{\mathrm{j}}\left(E_{\mathrm{i}}<E_{\mathrm{j}}\right)$, and the total charge $Q$ flow during the first $100 \mathrm{~ms}$ after the potential step was obtained by integrating the transition current. Note that the integration time, $100 \mathrm{~ms}$ [25], is long enough to complete the electron transfer from surface Fc groups to the Au substrate underneath, if the oxidation takes place. Various $E_{\mathrm{j}}$ were applied on the same SAMs in order to obtain the relationship between the charge $Q$ and the potential step width $\Delta E\left(=E_{\mathrm{j}}-E_{\mathrm{i}}\right.$.) as shown in Fig. 7. We assumed that no diffusing species was involved in the oxidation reaction; that is, each $Q$ value is the sum of the contributions from double layer charging $\left(Q_{\mathrm{dl}}\right)$ and from the oxidation of surface Fc groups $\left(Q_{\mathrm{FUT}}\right)$, i.e. $Q=Q_{\mathrm{dl}}+$ $Q_{\text {FUT. }}$ In cases where $E_{\mathrm{j}}$ is more positive than the oxidation wave of voltammograms, all the (electrochemically active) Fc groups of adsorbed FUT molecules should be oxidized to $\mathrm{Fc}^{+}$states by the potential-step from $E_{\mathrm{i}}$ to $E_{\mathrm{j}}$. Under such conditions, $Q_{\mathrm{FUT}}$ equals $n e A N_{\mathrm{FUT}}(\mathrm{Eq}(1))$. Or, given that all the FUT molecules are electrochemically active, then $Q_{\mathrm{FUT}}=n e A \Gamma_{\mathrm{FUT}} . \quad$ On the other hand, the double layer charge should be $Q_{\mathrm{dl}}$ $=C_{\mathrm{dl}} \Delta E$, if the double layer capacitance, $C_{\mathrm{dl}}$, can be assumed constant over the applied potential range. Thus a plot of $Q$ vs. $\Delta E$ gave a straight line (see dashed lines in Fig. 7) with an intercept of $Q_{\mathrm{FUT}}$ and a slope of $C_{\mathrm{dl}}$, when $E_{\mathrm{j}}$ was set after the oxidation wave. 
The $Q$ vs. $\Delta E$ plots for pure FUT SAM $\left(\chi_{\mathrm{FUT}}=1.0\right)$ measured in the aqueous $\mathrm{HClO}_{4}$ solution and TMHA-TFSA ionic liquid are shown in Fig. 7. While the onset shape of the two $Q$ vs. $\Delta E$ curves within the range $0 \leq \Delta E \leq 0.35 \mathrm{~V}$ resembled each other, subsequent curves at $\Delta E>0.35 \mathrm{~V}$ followed different trends. The curve for $\mathrm{HClO}_{4}$ solution kept the onset slope and gave a straight line at $\Delta E>0.55 \mathrm{~V}$. In contrast, the slope for TMHA-TFSA curve gradually decreased at $\Delta E>0.35 \mathrm{~V}$, and moved onto a straight line at $\Delta E=0.80 \mathrm{~V}$. As already evidenced by a set of CV (Fig. 3a and Fig. 5a), the $Q$ vs. $\Delta E$ curves also clearly demonstrated that the reaction $\left(\mathrm{Fc} \square \mathrm{Fc}^{+}+\mathrm{e}\right)$ in TMHA-TFSA takes place over $0.25 \mathrm{~V}(=0.80 \mathrm{~V}-0.55 \mathrm{~V})$ wider potential range. The most important thing is that the $Q_{\text {FUT }}$ values for both the electrolytes, estimated from the intercepts of the straight regions, are nearly equal and around $35 \mu \mathrm{C}$, which corresponds to $c$ a. $2.2 \times 10^{14} \mathrm{~cm}^{-2}$. This substantiated that, whether in the $\mathrm{HClO}_{4}$ solution or TMHA-TFSA, the surface density of electrochemical active FUT molecules is basically identical. The only thing that differs is the ease of oxidation. As was expected above, the value $Q_{\mathrm{FUT}} \approx 35 \mu \mathrm{C}$ was smaller than that estimated from $\mathrm{CV}: 45.1 \mu \mathrm{C}$ in $\mathrm{HClO}_{4}$ (Fig. 3a) and $40.0 \mu \mathrm{C}$ (Fig. 5a), probably due to the contribution of $C_{\mathrm{dl}}$. We believe, however, that the discussion as far as the preceding section, based only on the voltammetric study, is still valid on a semi-quantitative basis. According to the slope of the straight regions of the $Q$ vs. $\Delta E$ plot, $C_{\mathrm{dl}}$ for the $\mathrm{HClO}_{4}$ solution and TMHA-TFSA are 1.5 and $0.8 \mu \mathrm{F}$, respectively. While, in general, $C_{\mathrm{dl}}$ for conventional ionic liquids are generally larger than those for propylene carbonate (PC) solutions, they 
are smaller than those for aqueous solutions [31]. The present results are consistent with the trend.

Again, we have to emphasize that a wide electrochemical window of TFSA ${ }^{-}$based ILs rendered it possible to perform the potential-step experiments with large $\Delta E$. For the aqueous $\mathrm{HClO}_{4}$ solution and $\mathrm{EMI}^{-\mathrm{BF}_{4}}$ (data not shown) the step potential could not be enhanced beyond $0.7 \mathrm{~V}$ because of the decomposition of electrolytes.

\subsection{Cyclic voltammetry in mixed ionic liquids}

We described in Sections 3.2 and 3.3 that the electrochemical behaviors of binary SAMs in two ILs with TFSA ${ }^{-}$anion were similar to each other but different from those

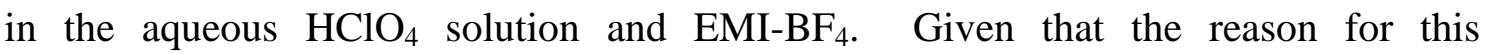
phenomenon is the difference of ion size between $\mathrm{TFSA}^{-}$anion and $\mathrm{BF}_{4}{ }^{-} / \mathrm{ClO}_{4}^{-}$, a simple addition of, for example, $\mathrm{EMI}_{-\mathrm{BF}_{4}}$ to EMI-TFSA, which is a partial replacement of TFSA ${ }^{-}$anions with $\mathrm{BF}_{4}^{-}$anions, should influence the redox behavior. Since such an experiment would provide positive support for our assumption, we prepared a series of mixed ILs electrolytes with EMI-TFSA and EMI-BF 4 , and a set of CV for two SAMs $\left(\chi_{\mathrm{FUT}}=1.0\right.$ and 0.1$)$ were measured in these electrolytes.

Figure $8 \mathrm{a}$ shows the CVs for pure FUT SAM $\left(\chi_{\mathrm{FUT}}=1.0\right)$. Here, an intriguing phenomenon occurred: a new peak was observed at the positive side of the original peak at about $+0.13 \mathrm{~V}$ vs. $\mathrm{Pt}$, once only a little amount of $\mathrm{BF}_{4}^{-}$anion $(0.1 \mathrm{vol} \%)$ was "doped" in EMI-TFSA electrolyte. It appeared that the long tail at high potential region was "shifted" into the new redox peaks that may well be attributable to the redox of FUT 
molecules under different $\mathrm{Fc}^{+}$-anion interaction. The potential of the new peak shifted negatively with reference to the original peak along with the increase in the amount of $\mathrm{BF}_{4}^{-}$anion, indicating that this reaction might occur more easily if more $\mathrm{BF}_{4}{ }^{-}$existed in the electrolyte. At the same time, no obvious shape change was recognized for the original peak at $-0.1 \mathrm{~V}$, but a slight shift was seen to the positive side. We suggest that the potential shift of the original peak is due to the negative shift of the immersion potential of $\mathrm{Pt}$ reference electrode by the addition of EMI-BF 4 , and hence is not an essential matter. In contrast, no additional peak appeared in CVs for SAMs with well-separated FUT molecules $\left(\chi_{\mathrm{FUT}}=0.1\right)$ as shown in Fig. $8 \mathrm{~b}$. Note that the shift of the original peak at $-0.12 \mathrm{~V}$ to the positive side is for the same reason as above.

Thus, an anionic effect was also clearly observed in this experiment, and there is little doubt that the difference in ion size of the two anions is the main reason for this interesting result. As illustrated by Fig. 9, the anions and cations that stayed in a random state (I) started to make ion pairs between anions and $\mathrm{Fc}^{+}$groups when the potential was swept positively. Here, (II) the FUT molecules at the domain boundary and a part of FUT inside the domain are oxidized first, and (III), as higher potential was applied, smaller $\mathrm{BF}_{4}^{-}$anions migrate to the remaining $\mathrm{Fc}$ groups to form new ion pairs in the remaining clustered FUT, instead of the TFSA ${ }^{-}$accumulating to form the second layer of anion in the case of TFSA ${ }^{-}$only electrolytes as shown in Fig. 6. Since it is an additional ion pairing process, a new redox peak occurs in this case. (IV) As a result, most of the remaining Fc groups are compensated for through ion pairing with a $\mathrm{BF}_{4}^{-}$ anion. Therefore, we noticed that $\mathrm{BF}_{4}{ }^{-}$anion has a thermodynamically more sensitive 
reaction property with clustered FUT moieties than $\mathrm{TFSA}^{-}$. For the SAMs with well-separated FUT molecules $\left(\chi_{\mathrm{FUT}}=0.1\right)$, all Fc groups were compensated for at the first step, so no extra peak appeared irrespective of whether $\mathrm{BF}_{4}{ }^{-}$anion was added or not.

In consequence, anion size can provide a plausible explanation of the intriguing behavior in mixed electrolytes. However, several questions remain unsolved: For example, which anion, $\mathrm{TFSA}^{-}$or $\mathrm{BF}_{4}^{-}$, formed the ion pair at the first step? Since the shape, i.e. height and area, of the original peak did not change, it can be assumed that TFSA ${ }^{-}$contributed to this part of the reaction. But it is difficult to believe that $\mathrm{BF}_{4}^{-}$ with higher reactive property lost the competition in forming an ion pair with large-sized TFSA ${ }^{-}$. We suggest that additional study should be conducted on this matter, such as EQCM measurement [6], to assess the amounts of ion-paired anions. Also, anions with various sizes should be compared in future experiments to underpin the assumption.

\section{Conclusions}

In the present study, the electrochemical behaviors of FUT/UDT binary SAMs were examined in three different ILs electrolytes and aqueous $\mathrm{HClO}_{4}$ solution. Although most of the measurements that we conducted were a series of conventional $\mathrm{CV}$, the difference in the redox behaviors of Fc groups at the surface of the SAMs was consistently elucidated by the interaction between the Fc groups and anions of 
electrolytes. For example, CV for FUT-rich SAMs in TFSA ${ }^{-}$based ILs gave a smaller peak height and a long tail toward higher potential range. Such behaviors were explained by the assumption that, due to steric hindrance, large-sized TFSA ${ }^{-}$anions cannot fully compensate for the positive charge that emerges when the surface Fc groups are oxidized to $\mathrm{Fc}^{+}$state. When higher potentials are applied, more $\mathrm{TFSA}^{-}$ anions would accumulate in the vicinity of the SAMs surface, and the consequent enhanced negative charge density would allow compensation of all the surface Fc groups if oxidized. This assumption was supported by the facts that $(i)$ the behaviors disappeared if the surface FUT molecules were diluted so that sufficient spaces were left around each Fc group and (ii) the presence of smaller $\mathrm{BF}_{4}^{-}$ions "stimulated" the oxidation at lower potentials. A series of CVs for FUT SAMs immersed in mixed ILs with $\mathrm{TFSA}^{-}$and $\mathrm{BF}_{4}^{-}$anions showed a new redox peak, clearly demonstrating that smaller $\mathrm{BF}_{4}^{-}$ions can compensate the $\mathrm{Fc}^{+}$states more readily than $\mathrm{TFSA}^{-}$. It is important that the total redox charge $Q_{\mathrm{FUT}}$, which corresponds to the surface density of FUT, for the same mixed SAM is nearly independent of the electrolyte used for the CV measurement if the $Q_{\mathrm{FUT}}$ values are obtained by integration with an adequate integral range. Seen the other way around, it is possible to underestimate the surface density of FUT if the integration range is set based on CVs in TFSA" based ILs with a "common sense" narrower potential scan range like the case of Fig. 3. CV is a useful method to estimate the surface density of adsorbed electrochemically active species, but we have to consider the scan range when some ILs are employed. On the other hand, we also noticed, in the present study, that ILs with wide electrochemical windows provide 
beneficial electrochemical circumstances where no redox reaction(s) other than that of redox-active SAMs occurs over a wide potential range. In the case of the potential-step chronocoulometry (Fig. 7), for example, the step width $\Delta E$ could not exceed $0.7 \mathrm{~V}$ in the aqueous $\mathrm{HClO}_{4}$ solution because an additional anodic reaction starts. While a number of issues remain unsolved, ILs should prove to be an essential tool for the application of these SAMs in the future.

\section{Acknowledgments}

We wish to thank Professor Takashi Kakiuchi (Kyoto University) for his valuable comments on this work. The work was partly supported by Kyoto University Global COE Program, "International Center for Integrated Research and Advanced Education in Materials Science" from the Ministry of Education, Culture, Sports, Science, and Technology of Japan. 


\section{References}

[1] Z. Feng, S. Imabayashi, T. Kakiuchi, K. Niki, J. Chem. Soc., Faraday Trans. 93 (1997) 1367-1370.

[2] K.M. Roth, J.S. Lindsey, D.F. Bocian, W.G. Kuhr, Langmuir 18 (2002) 4030-4040.

[3] C.E.D. Chidsey, Science 251 (1991) 919-922.

[4] X. Yao, J. Wang, F. Zhou, J. Wang, N. Tao, J. Phys. Chem. B 108 (2004) $7206-7212$.

[5] K. Uosaki, Y. Sato, H. Kita, Langmuir 7 (1991) 1510-1514.

[6] K. Shimazu, I. Yagi, Y. Sato, K. Uosaki, J. Electroanal. Chem. 372 (1994) 117-125.

[7] G.K. Rowe, S.E. Creager, Langmuir 7 (1991) 2307-2312.

[8] L.Y.S. Lee, R.B. Lennox, Langmuir 23 (2007) 292-296.

[9] H.O. Finklea, D.D. Hanshew, J. Am. Chem. Soc. 114 (1992) 3173-3181.

[10] D.M. Collard, M.A. Fox, Langmuir 7 (1991) 1192-1197.

[11] L.Y.S. Lee, T.C. Sutherland, S. Rucareanu, R.B. Lennox, Langmuir 22 (2006) $4438-4444$.

[12] S.E. Creager, G.K. Rowe, Anal. Chim. Acta 246 (1991) 233-239.

[13] M. Freemantle, Chem. Eng. News 78(20, May 15) (2000) 37-50.

[14] T. Katase, R. Kurosaki, K. Murase, T. Hirato, Y. Awakura, Electrochem. Solid-State Lett. 9 (2006) C69-C72.

[15] K. Murase, R. Kurosaki, T. Katase, H. Sugimura, T. Hirato, Y. Awakura, J. Electrochem. Soc. 154 (2007) D612-D616.

[16] H. Matsumoto, in: H. Ohno (Ed.), Electrochemical Aspects of Ionic Liquids, Wiley Interscience, Hoboken, NJ, 2005, pp. 35-54.

[17] H. Ohno, in: F. Endres, A.P. Abbott, D.R. MacFarlane (Eds.), Electrodeposition from Ionic Liquids, Wiley-VCH, Weinheim, 2008, pp. 47-53.

[18] J. Dai, J. Cheng, J. Jin, Z. Li, J. Kong, S. Bi, Electrochem. Commun. 10 (2008) $587-591$.

[19] D. Oyamatsu, T. Fujita, S. Arimoto, H. Muankata, H. Matsumoto, S. Kuwabata, J. Electroanal. Chem. 615 (2008) 110-116. 
[20] J. Li, Y. Shen, Y. Zhang, Y. Liu, Chem. Commun. (2005) 360-362.

[21] B.J. Clark, W.E. Cleland, C.L. Hussey, J. Electrochem. Soc. 139 (1992) L107-L108.

[22] G. Valincius, G. Niaura, B. Kazakevičienè, Z. Talaikytė, M. Kažemėkaitė, E. Butkus, V. Razumas, Langmuir 20 (2004) 6631-6638.

[23] K. Murase, K. Nitta, T. Hirato, Y. Awakura, J. Appl. Electrochem. 31 (2001) 1089-1094.

[24] A.J. Bard, L.R. Faulkner, Electrochemical Methods, Fundamentals and Applications, 2nd ed., John Wiley \& Sons, New York, 2001, p. 53.

[25] M.T. Stankovich, A.J. Bard, J. Electroanal. Chem. 86 (1978) 189-199.

[26] A.J. Bard, L.R. Faulkner, Electrochemical Methods, Fundamentals and Applications, 2nd ed., John Wiley \& Sons, New York, 2001, p. 605.

[27] T. Kakiuchi, M. Iida, D. Hobara, S. Imabayashi, K. Niki, Langmuir 17 (2001) 1599-1603.

[28] S. Fujii, S. Kurokawa, K. Murase, K-H. Lee, A. Sakai, H. Sugimura, Electrochim. Acta 52 (2007) 4436-4442.

[29] C.E.D. Chidsey, C.R. Bertozzi, T.M. Putvinski, A.M. Mujsce, J. Am. Chem. Soc. 112 (1990) 4301-4306.

[30] M. Ue, J. Electrochem. Soc. 141 (1994) 3336-3342.

[31] C. Nanjundiah, S.F. McDevitt, V.R. Koch, J. Electrochem. Soc. 144 (1994) 3392-3397. 


\section{Figure captions}

Fig. 1. XPS Fe $2 p$ and $S 2 p$ spectra for FUT/UDT binary SAMs prepared through the immersion of Au substrate in ethanol solutions with five different FUT mole fractions, $\chi_{\text {FUT. }} \quad$ The spectra for pure FUT SAM $\left(\chi_{\text {FUT }}=1.0\right)$, pure UDT SAM $\left(\chi_{\mathrm{FUT}}=0.0\right)$, and bare Au substrate are also indicated.

Fig. 2. Plots of Fe/S atomic composition ratio (squares, left axis) and surface coverage of FUT, $\Gamma_{\text {FUT }}$ (circles, right axis), against FUT mole fraction, $\chi_{\mathrm{FUT}}$, in solution used for SAM preparation. The Fe/S ratios were obtained by XPS composition analysis where the Fe/S ratio for pure FUT SAM $\left(\chi_{\mathrm{FUT}}=1.0\right)$ was normalized to be 1.0 , while the coverage data were estimated by the integration of each oxidative peak area of cyclic voltammograms obtained in aqueous $0.1 \mathrm{M} \mathrm{HClO}_{4}$ solution (Fig. 3a).

Fig. 3. Cyclic voltammograms for FUT/UDT binary SAMs measured in four different electrolytes: (a) aqueous $0.1 \mathrm{M} \mathrm{HClO}_{4}$ solution, (b) $\mathrm{EMI}^{-\mathrm{BF}_{4}}$ ionic liquid, (c) TMHA-TFSA ionic liquid, and (d) EMI-TFSA ionic liquid. Scan rate was $0.1 \mathrm{~V} \mathrm{~s}^{-1}$ and scanned potential range was $0.6 \mathrm{~V}$ for all runs. The SAMs were prepared through the immersion of $\mathrm{Au}$ substrate in ethanol solutions with five different FUT mole fractions, $\chi_{\mathrm{FUT}}$.

Fig. 4. Surface density, $N_{\text {FUT }}$, of electrochemically active FUT species in (a) four different electrolytes and (b) two TFSA ${ }^{-}$based ILs of the four, estimated by Eq. (1) (see 
the text) from total electricity $(Q)$ for $\mathrm{Fc} \square \mathrm{Fc}^{+}+$e oxidation. Each $Q$ value was obtained by integrating the oxidative peak of the cyclic voltammogram measured with (a) normal potential range (Fig. 3) and (b) enlarged potential range (Fig. 5). In (b), the data for the normal potential range are also indicated for comparison.

Fig. 5. Cyclic voltammograms measured with wide potential scan range for FUT-rich FUT/UDT binary SAMs $\left(\chi_{\text {FUT }} \geq 0.5\right)$ in (a) TMHA-TFSA and (b) EMI-TFSA ionic liquids; scan rate and scanned potential range were $0.1 \mathrm{~V} \mathrm{~s}^{-1}$ and $1.1 \mathrm{~V}$, respectively. Voltammograms with normal scan range (same as Fig. 3 ) for FUT-deprived SAM $\left(\chi_{\text {FUT }}\right.$ $=0.1)$ and pure UDT SAM $\left(\chi_{\mathrm{FUT}}=0.0\right)$ are also indicated for comparison.

Fig. 6. Schematic illustration of the change in the alignment of $\mathrm{TFSA}^{-}$anions at the surface of pure FUT SAM $\left(\chi_{\mathrm{FUT}}=1.0\right)$ during the redox of ferrocenyl $(\mathrm{Fc})$ groups under enlarged potential scan as in Fig. 5.

Fig. 7. A typical $Q\left(=Q_{\mathrm{dl}}+Q_{\mathrm{FUT}}\right)$ vs. $\Delta E\left(=E_{\mathrm{j}}-E_{\mathrm{i}}\right)$ plot obtained by potential-step chronocoulometry for pure FUT SAM $\left(\chi_{\mathrm{FUT}}=1.0\right)$ in aqueous $0.1 \mathrm{M} \mathrm{HClO}_{4}$ and TMHA-TFSA ionic liquid electrolytes. The initial potentials $E_{\mathrm{i}}$ were set before oxidation peak of voltammograms (Fig. 3a and 3c): $0.0 \mathrm{~V}$ vs. $\mathrm{Ag} / \mathrm{AgCl}(3 \mathrm{M} \mathrm{NaCl})$ for aqueous $0.1 \mathrm{M} \mathrm{HClO}_{4}$ and $-0.3 \mathrm{~V}$ vs. Pt in TMHA-TFSA.

Fig. 8. Cyclic voltammograms for (a) pure FUT SAM $\left(\chi_{\mathrm{FUT}}=1.0\right)$ and (b) FUT-dispersed SAM $\left(\chi_{\mathrm{FUT}}=0.1\right)$ measured in EMI-TFSA ionic liquids containing 0 , 
$0.1,1$, and 10 vol\% EMI-BF 4 Pt wires immersed in each pure/mixed IL was used as quasi-reference electrode. Scan rate was $0.1 \mathrm{~V} \mathrm{~s}^{-1}$. The SAMs were prepared through the immersion of Au substrate in ethanol solutions with corresponding FUT mole fractions, $\chi_{\text {FUT }}$.

Fig. 9. Schematic illustration of the change in the alignment of $\mathrm{TFSA}^{-}$and $\mathrm{BF}_{4}^{-}$ anions at the surface of pure FUT SAM $\left(\chi_{\mathrm{FUT}}=1.0\right)$ during the redox of ferrocenyl $(\mathrm{Fc})$ groups under potential scan as in Fig. 8. 


\section{Table 1}

XPS quantitative analysis for binary FUT/UDT SAMs prepared through the immersion of $\mathrm{Au}$ substrate in ethanol solutions containing five different FUT mole fractions, $\chi_{\mathrm{FUT}}$. $\mathrm{Fe} / \mathrm{S}$ atomic ratio gives a measure of the surface coverage of FUT, hence the ratios were normalized by the value for pure FUT SAM $\left(\chi_{\mathrm{FUT}}=1.0\right)$ as indicated in the rightmost column.

\begin{tabular}{|c|c|c|c|c|c|c|}
\hline \multirow[b]{2}{*}{$\chi_{\text {FUT }}$} & \multicolumn{4}{|c|}{ Atomic composition, at.\% } & \multirow[b]{2}{*}{$\mathrm{Fe} / \mathrm{S}$} & \multirow{2}{*}{$\begin{array}{c}\text { Normalized } \\
\mathrm{Fe} / \mathrm{S} \\
\end{array}$} \\
\hline & $\mathrm{Fe}$ & $\mathrm{S}$ & $\mathrm{C}$ & $\mathrm{Au}$ & & \\
\hline 1.0 & 2.5 & 1.6 & 51.0 & 40.3 & 1.61 & 1.00 \\
\hline 0.9 & 2.2 & 1.7 & 51.0 & 40.4 & 1.32 & 0.82 \\
\hline 0.5 & 1.8 & 1.7 & 48.9 & 42.6 & 1.03 & 0.64 \\
\hline 0.1 & 0.7 & 2.5 & 45.1 & 45.8 & 0.28 & 0.17 \\
\hline 0.0 & 0.0 & 2.5 & 42.8 & 51.1 & 0.00 & 0.00 \\
\hline
\end{tabular}



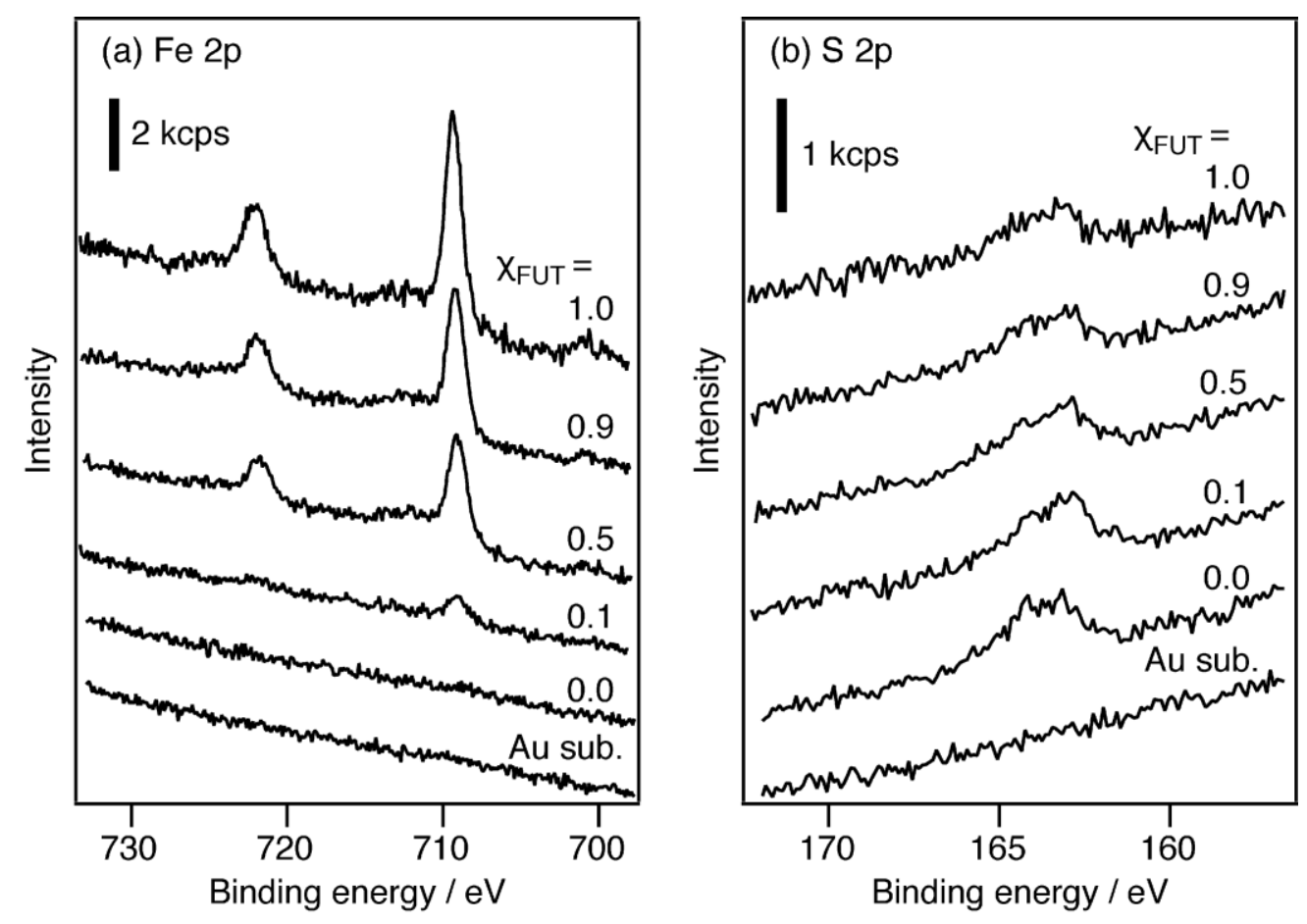

Fig. 1. XPS Fe $2 p$ and $S 2 p$ spectra for FUT/UDT binary SAMs prepared through the immersion of Au substrate in ethanol solutions with five different FUT mole fractions, $\chi_{\text {FUT. }}$ The spectra for pure FUT SAM $\left(\chi_{\text {FUT }}=1.0\right)$, pure UDT SAM $\left(\chi_{\text {FUT }}=0.0\right)$, and bare Au substrate are also indicated. 


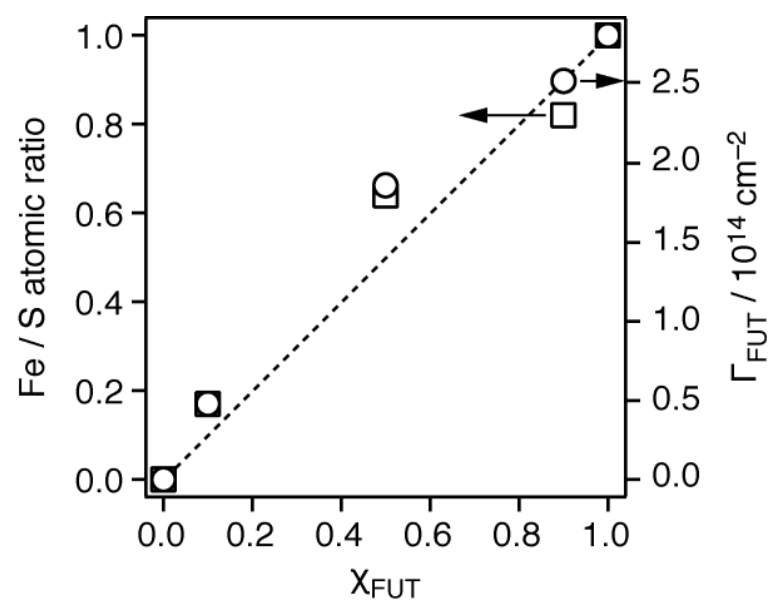

Fig. 2. Plots of Fe/S atomic composition ratio (squares, left axis) and surface coverage of FUT, $\Gamma_{\text {FUT }}$ (circles, right axis), against FUT mole fraction, $\chi_{\mathrm{FUT}}$, in solution used for SAM preparation. The Fe/S ratios were obtained by XPS composition analysis where the $\mathrm{Fe} / \mathrm{S}$ ratio for pure FUT SAM $\left(\chi_{\mathrm{FUT}}=1.0\right)$ was normalized to be 1.0 , while the coverage data were estimated by the integration of each oxidative peak area of cyclic voltammograms obtained in aqueous $0.1 \mathrm{M} \mathrm{HClO}_{4}$ solution (Fig. 3a). 

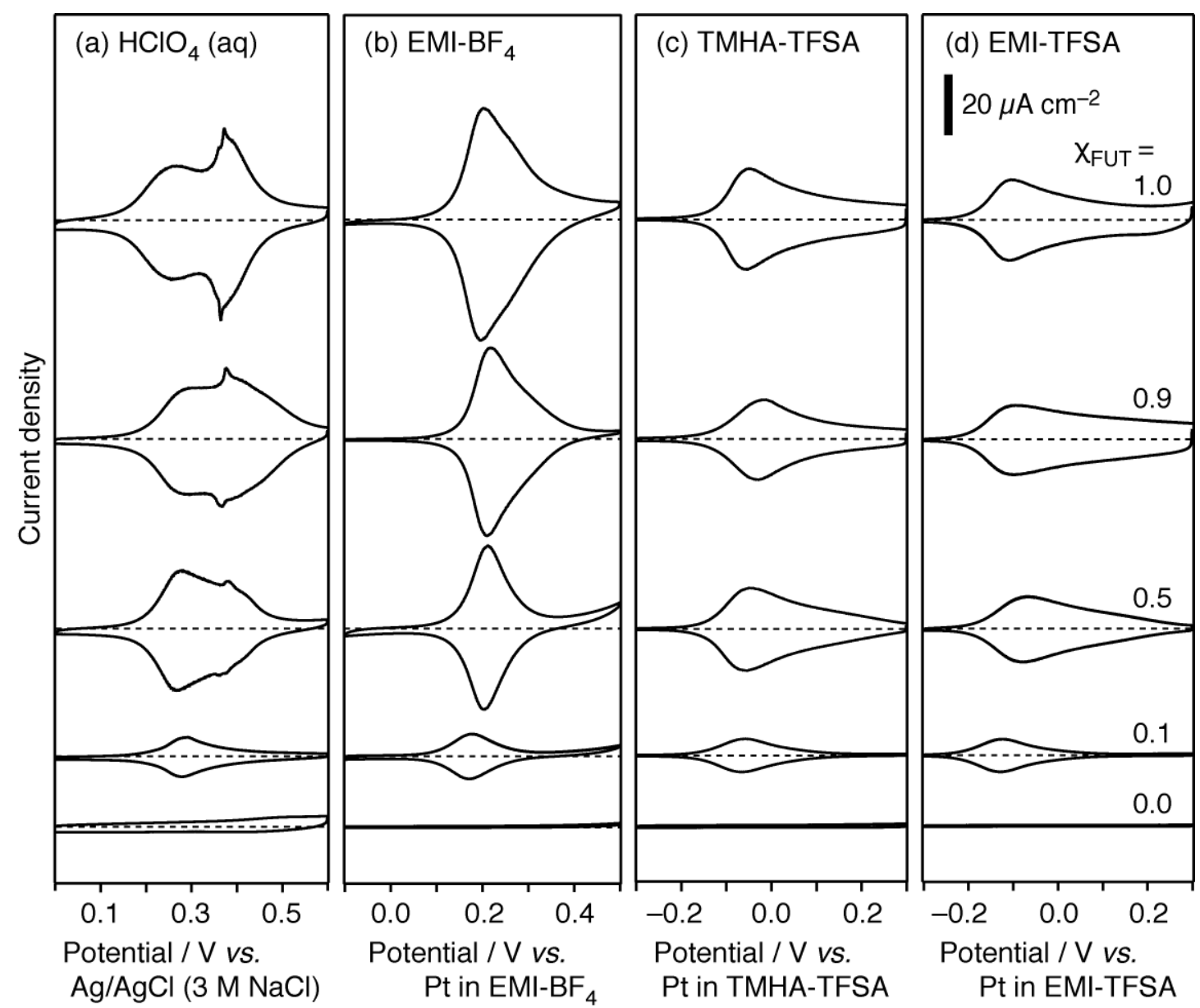

Fig. 3. Cyclic voltammograms for FUT/UDT binary SAMs measured in four different electrolytes: (a) aqueous $0.1 \mathrm{M} \mathrm{HClO}_{4}$ solution, (b) $\mathrm{EMI}_{-\mathrm{BF}_{4}}$ ionic liquid, (c) TMHA-TFSA ionic liquid, and (d) EMI-TFSA ionic liquid. Scan rate was $0.1 \mathrm{~V} \mathrm{~s}^{-1}$ and scanned potential range was $0.6 \mathrm{~V}$ for all runs. The SAMs were prepared through the immersion of $\mathrm{Au}$ substrate in ethanol solutions with five different FUT mole fractions, $\chi_{\mathrm{FUT}}$. 
(a)

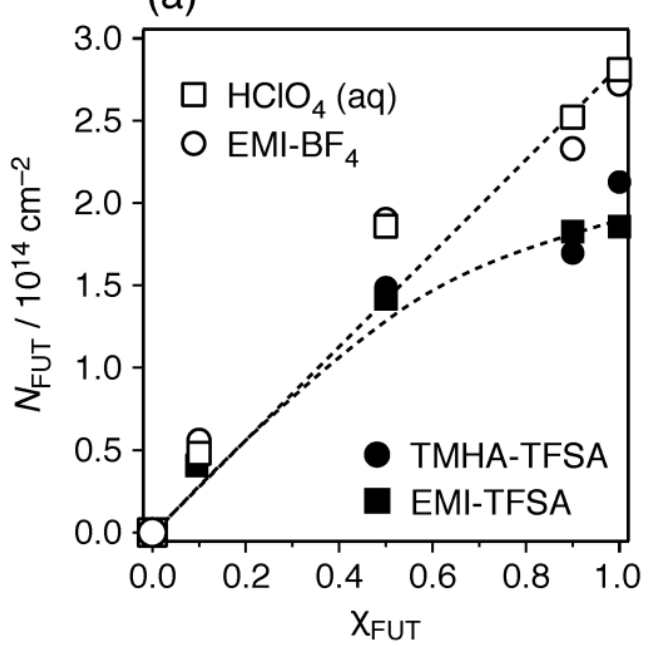

(b)

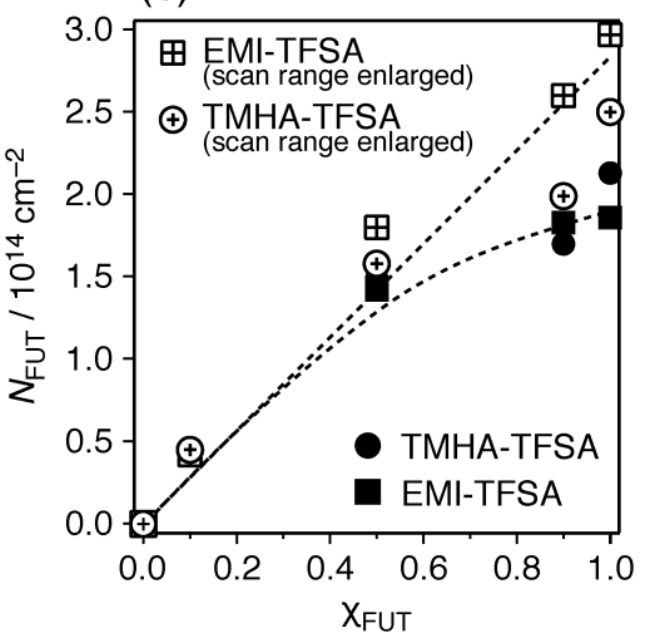

Fig. 4. Surface density, $N_{\mathrm{FUT}}$, of electrochemically active FUT species in (a) four different electrolytes and (b) two TFSA ${ }^{-}$based ILs of the four, estimated by Eq. (1) (see the text) from total electricity $(Q)$ for $\mathrm{Fc} \square \mathrm{Fc}^{+}+\mathrm{e}$ oxidation. Each $Q$ value was obtained by integrating the oxidative peak of the cyclic voltammogram measured with (a) normal potential range (Fig. 3) and (b) enlarged potential range (Fig. 5). In (b), the data for the normal potential range are also indicated for comparison. 

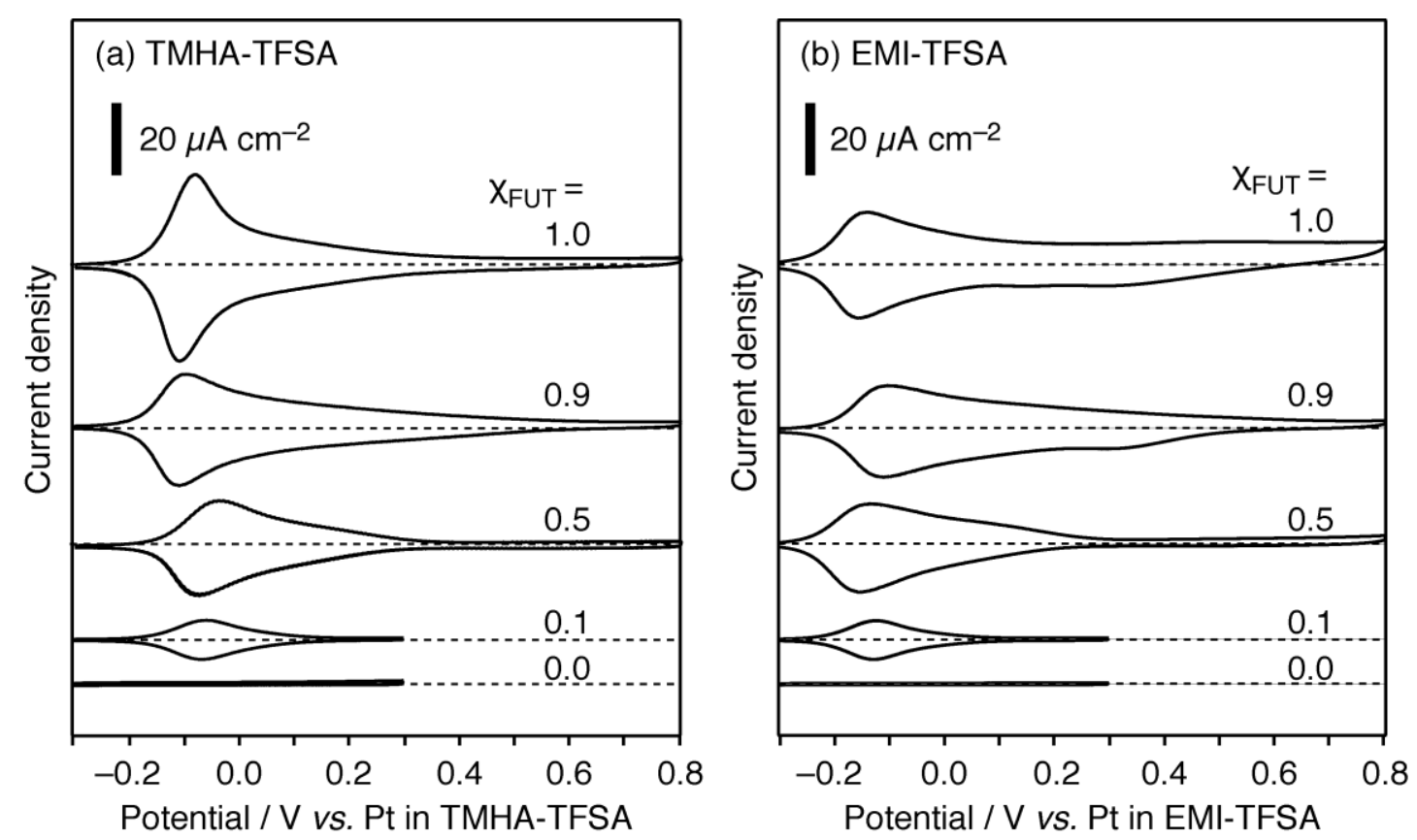

Fig. 5. Cyclic voltammograms measured with wide potential scan range for FUT-rich FUT/UDT binary SAMs $\left(\chi_{\mathrm{FUT}} \geq 0.5\right)$ in (a) TMHA-TFSA and (b) EMI-TFSA ionic liquids; scan rate and scanned potential range were $0.1 \mathrm{~V} \mathrm{~s}^{-1}$ and $1.1 \mathrm{~V}$, respectively. Voltammograms with normal scan range (same as Fig. 3) for FUT-deprived SAM ( $\chi_{\text {FUT }}$ $=0.1)$ and pure UDT SAM $\left(\chi_{\mathrm{FUT}}=0.0\right)$ are also indicated for comparison. 


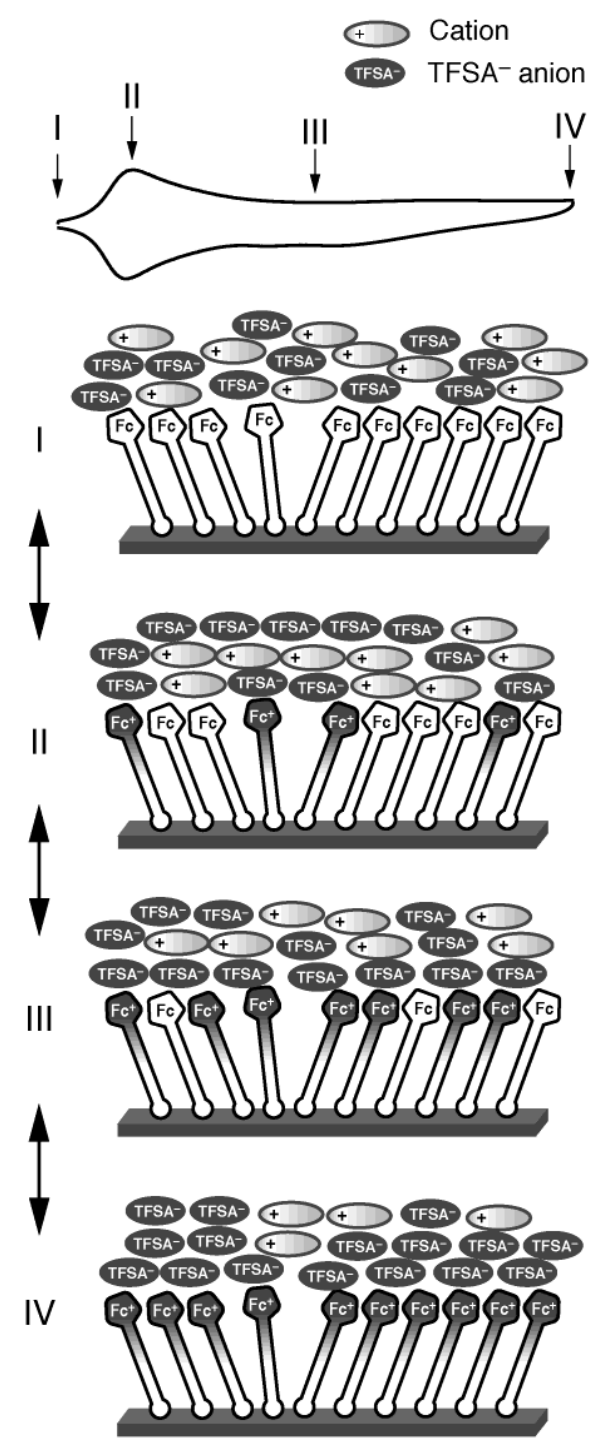

Fig. 6. Schematic illustration of the change in the alignment of TFSA ${ }^{-}$anions at the surface of pure FUT SAM $\left(\chi_{\mathrm{FUT}}=1.0\right)$ during the redox of ferrocenyl $(\mathrm{Fc})$ groups under enlarged potential scan as in Fig. 5. 


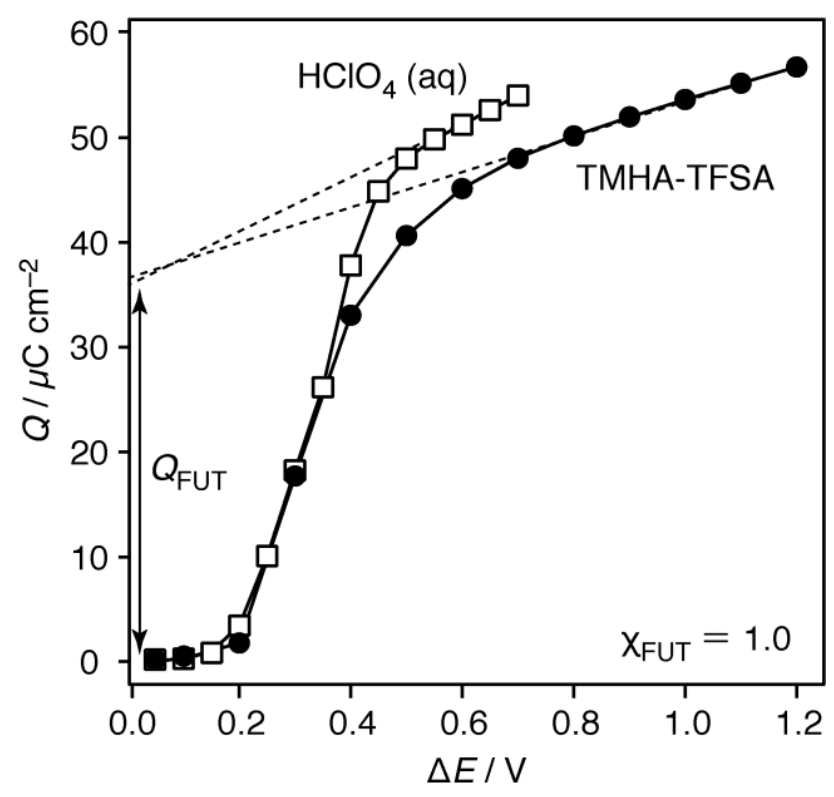

Fig. 7. A typical $Q\left(=Q_{\mathrm{dl}}+Q_{\mathrm{FUT}}\right)$ vs. $\Delta E\left(=E_{\mathrm{j}}-E_{\mathrm{i}}\right)$ plot obtained by potential-step chronocoulometry for pure FUT SAM $\left(\chi_{\mathrm{FUT}}=1.0\right)$ in aqueous $0.1 \mathrm{M} \mathrm{HClO}_{4}$ and TMHA-TFSA ionic liquid electrolytes. The initial potentials $E_{\mathrm{i}}$ were set before oxidation peak of voltammograms (Fig. $3 \mathrm{a}$ and 3c): $0.0 \mathrm{~V}$ vs. $\mathrm{Ag} / \mathrm{AgCl}(3 \mathrm{M} \mathrm{NaCl})$ for aqueous $0.1 \mathrm{M} \mathrm{HClO}_{4}$ and $-0.3 \mathrm{~V}$ vs. Pt in TMHA-TFSA. 

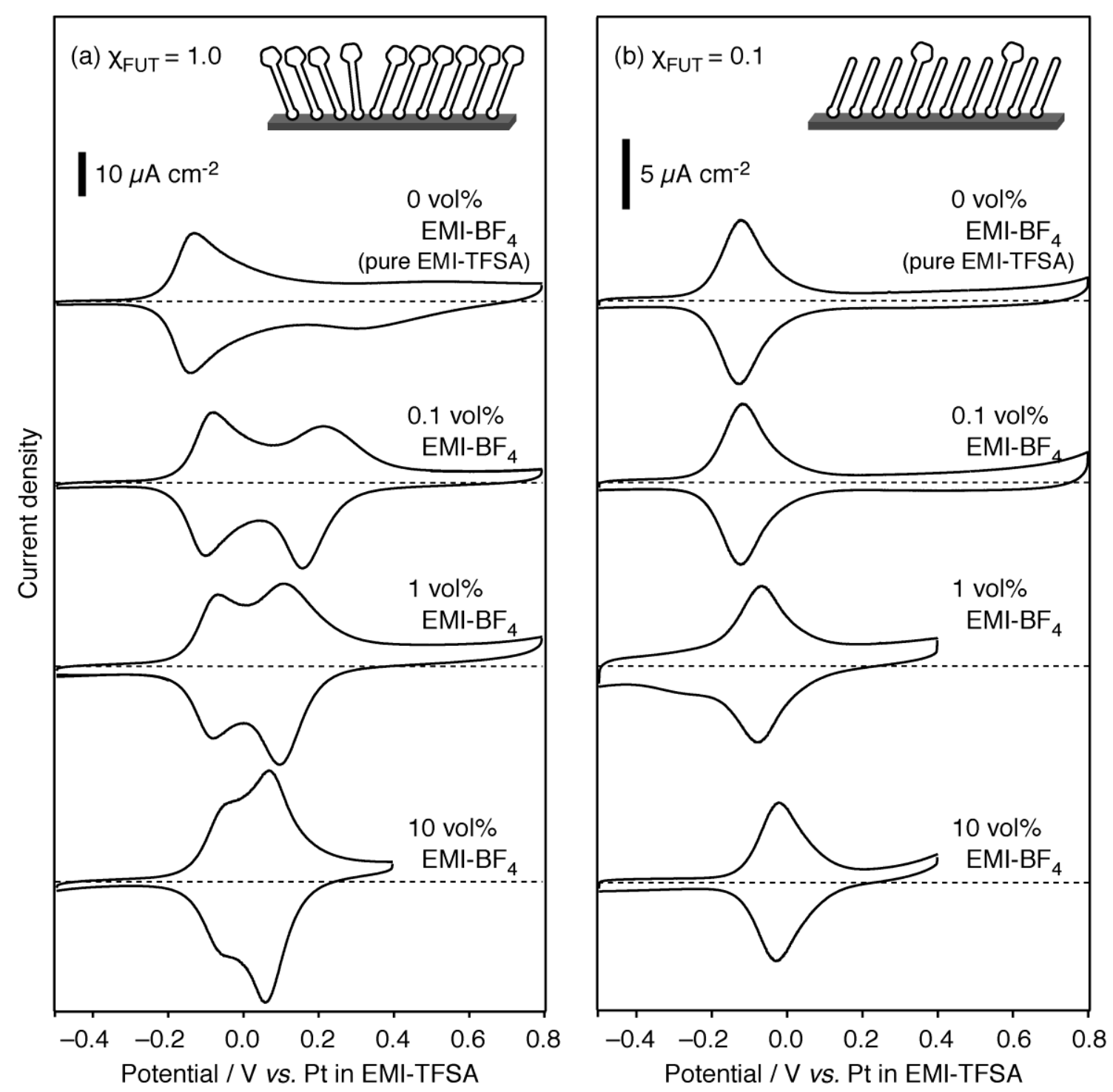

Fig. 8. Cyclic voltammograms for (a) pure FUT SAM $\left(\chi_{\mathrm{FUT}}=1.0\right)$ and (b) FUT-dispersed SAM $\left(\chi_{\mathrm{FUT}}=0.1\right)$ measured in EMI-TFSA ionic liquids containing 0 , $0.1,1$, and 10 vol\% EMI-BF 4 . Pt wires immersed in each pure/mixed IL was used as quasi-reference electrode. Scan rate was $0.1 \mathrm{~V} \mathrm{~s}^{-1}$. The SAMs were prepared through the immersion of Au substrate in ethanol solutions with corresponding FUT mole fractions, $\chi_{\text {FUT }}$. 


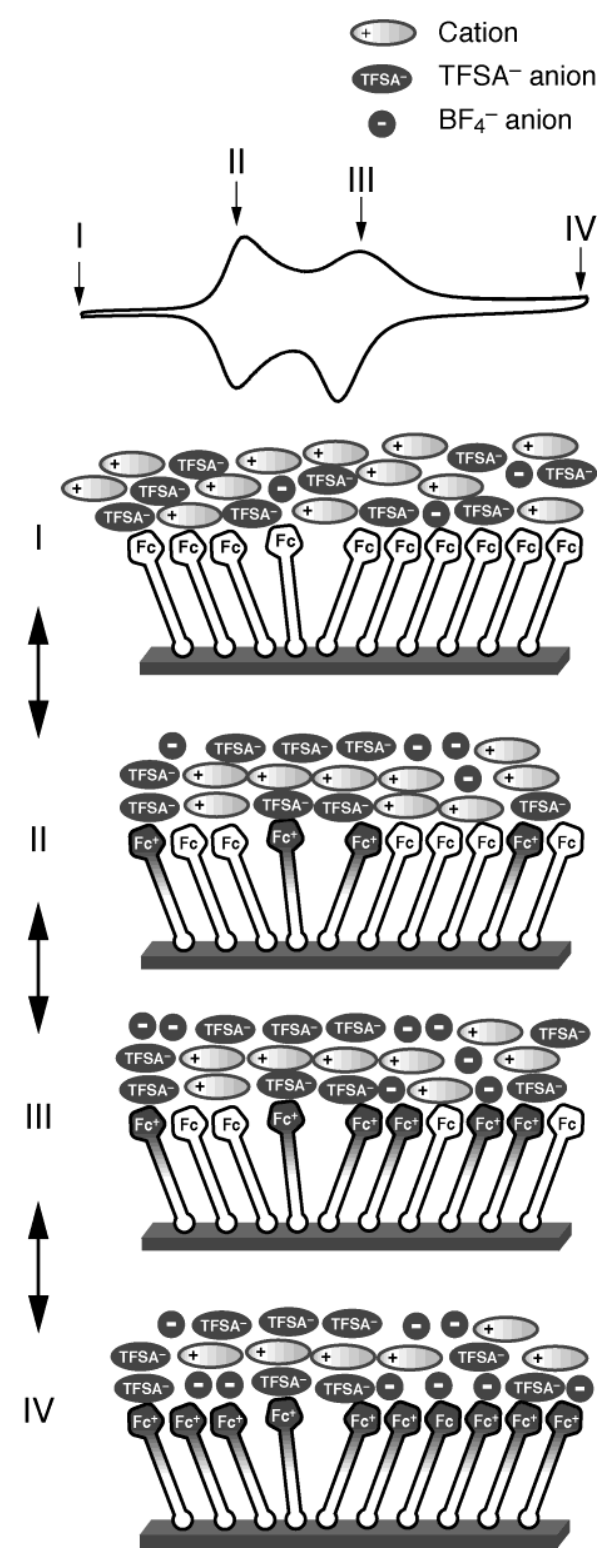

Fig. 9. Schematic illustration of the change in the alignment of $\mathrm{TFSA}^{-}$and $\mathrm{BF}_{4}^{-}$ anions at the surface of pure FUT SAM $\left(\chi_{\mathrm{FUT}}=1.0\right)$ during the redox of ferrocenyl $(\mathrm{Fc})$ groups under potential scan as in Fig. 8. 